\title{
A laboratory for design-directed research. Building design scholarship and academic possibility through designing
}

\author{
Mick Abbott, Jacky Bowring \\ Lincoln University, New Zealand \\ School of Landscape Architecture \\ mick.abbott@lincoln.ac.nz | jacky.bowring@lincoln.ac.nz
}

\begin{abstract}
Designing is an experimental practice. Eschewing traditional concepts of designing as simply solving problems, and ideas of research as a positivist pursuit of truth, Landscope DesignLab embraces an expansive perspective of design-directed research. Using the tools of questioning, collaborating, designing, grounding and communicating, the DesignLab explores the terrains of possibility. Working within an inter-disciplinary milieu fosters strong connections, and seizes the generative possibilities of problems, questions, absences, and data.
\end{abstract}

Keywords: design-directed research, innovation, collaboration.

To cite this article:

Abbott, M. and Bowring, J. (2017). A laboratory for design-directed research. Building design scholarship and academic possibility through designing. The Journal of Public Space, 2(3), Special Issue, 4I-52, DOI: 10.5204/jps.v2i3. I I2

This article has been peer-reviewed and accepted for publication in The Journal of Public Space. Please see the Editorial Policies under the 'About' section of the journal website for further information. 
Within university-contexts, design is increasingly being framed as experimental. There is a shift from the exemplary to the investigative, and from the singular outcome to a suite of scenarios'. It is within this changing constitution of design research that Lincoln University's Landscope DesignLab operates. Design as Laboratory presents a challenge for those who continue to consider design as merely in the service of 'solving a problem,' or design outcomes providing the content for examination as a case study or exemplar. Each absents design's value as a vehicle for exploring new terrain.

The challenges of design-directed research are amplified in spatial design disciplines, as research methods have traditionally been borrowed from other academic paradigms with design as the 'subject' of research, rather than the 'method.' Here, within an Aotearoa New Zealand perspective research audits of universities reinforce such norms. In the most recent review of research quality that covered research activity across all of New Zealand's tertiary sector, design outputs accounted for $0.46 \%$ of all major 'nominated research outputs' while journal articles and book chapters totalled $75.8 \%{ }^{2}$ In research, design and synthesis are arguably more readily described than applied as a method of inquiry.

The challenge is to transform a research paradigm in which, as Carter so deftly puts it, "knowledge and creativity are conceived as mutually exclusive". ${ }^{3}$ Carter observes that "while 'creative research' ought to be a tautology, in the present cultural climate it is in fact an oxymoron". ${ }^{4}$ The key here is that the relationship is only oxymoronic in the 'present cultural climate,' reflecting the way in which the prevailing positivist paradigm dominates research activity. Researchers within creative disciplines are often faced with the challenge of needing to quantify or defend 'research outputs' in terms that come from the language of positivist science.

The problem is that, according to creative practice researcher Steve Strange, “'Creativity' is seen as an amorphous, irrational concept; 'research' a rationalising force tied to the institutional nature of the academy". This split between creativity and knowledge is recent and reflects the scientific paradigm of the last couple of centuries. The severing of the subject and the object has much to answer for in terms of the de-coupling of creativity and knowledge. Agamben reminds us that, "For Antiquity, the imagination, which is now expunged from knowledge as 'unreal,' was the supreme medium of knowledge". 6

Further, when design research is considered there is a tendency in design disciplines to focus scholarship on the discursive framing and reframing of what design research is. This results in an implicit academic caution; that until design's role in research is collectively defined and agreed to, attempts to research through designing should be deferred. This

\footnotetext{
' Richard Weller, "Boomtown 2050: Scenarios for a rapidly growing city". Richard Weller and Tatum Hands, Building the Global Forest.

${ }^{2}$ Tertiary Education Commission, Performance-Based Research Fund Evaluating Research Excellence - the 2012 Assessment, (Wellington New Zealand, 2013), 32.

${ }^{3}$ Paul Carter. Material thinking: The theory and practice of creative research (Melbourne: Melbourne University Press, 2004), 8.

${ }^{4}$ Paul Carter, Material thinking, 7.

${ }^{5}$ Shane Strange. "Creative research: A radical subjectivity?," TEXT Special Issue I4 (20I2), accessed I7

March 2014 http://www.textjournal.com.au/speciss/issuel4/Strange.pdf, 5.

${ }^{6}$ Giorgio Agamben Infancy and History: On the Destruction of Experience (London: Verso, I993), II.
} 
intent, while noble, keeps design disciplines at the door of a mode of inquiry that the field is yet to enter.

Yet examining and experimenting in the role of designing in research remains important. Back in 200I Lily Chi set through five interrelated questions a skeletal framework for considering research through designing: "In what ways can design work's very specificity and finitude offer a medium of investigation for questions of broad concern? How do the creative and discursive interact? How does individual imagination figure in the deliberation of sociocultural matters? What role does the created artefact play in the conjectural process? How, in short, can design as design be practised - and read - as a pursuit of knowledge, understanding?" (Chi 200I: 250)

In the School of Landscape Architecture at Lincoln University, Landscope Designlab is actively pursuing a research agenda where design is its core research method. Students and staff within the DesignLab explore research questions in ways that foster collective endeavour, and include research and researchers from other disciplinary areas. In this both landscape architecture and architecture offer a potent context for operating a laboratory approach, since it is a discipline built on the nexus of art and science. As design theorist Richard Buchanan argues, drawing upon the observations of John Dewey, it is precisely this interplay between science and art that is key to embracing design-directed research. Contrary to a positivist position, it is not, as Buchanan points out "science as primary and art as secondary".

Landscope DesignLab seeks to examine, and in the process consider the capacity of design-directed research to generate options, opportunities and value other than those being identified elsewhere. In this paper we discuss projects undertaken with the DesignLab, including Ararira/Yarrs, The Eden Project New Zealand, and Punakaiki. We identify five strategies that are core to research within a design laboratory: questioning, collaborating, designing, grounding and communicating.

\section{Questioning}

Research can be too often motivated by the presumption of finding (and asserting) The Answer. However, a key strategy for building value is to frame projects around a process of active questioning. Sarah Whatmore describes this as "the joy of not knowing". "And as landscape theorist Thomas Oles puts it, "Do not rush to answers, savour the asking". We draw on the insight of the field of design thinking, which recognises the need to challenge this 'rush to answers,' and instead recognises the value in not over-simplifying the problem.

Design theorist Charles Owen's identifies the importance of explicitly exploring the framing of problems before they are solved; to first ask 'what to make?' before leaping towards "how to make it?" ${ }^{0}$ Owen explains that the abbreviation of design thinking, so

\footnotetext{
${ }^{7}$ Richard Buchanan, "Wicked Problems in Design Thinking," Design Issues Vol. 8, n. 2 (I992): 5-2I, 7.

${ }^{8}$ Sarah Whatmore 'Generating Materials,'. in M. Pryke, G. Rose \& S. Whatmore (Eds.), Using social theory : thinking through research (London ; Thousand Oaks, Calif.: SAGE in association with the Open University, 2003), 98. [her emphasis].

9 Thomas Oles Go with Me: 50 Steps to Landscape Thinking. (Amsterdam: Architectura \& Natura Publishers, 2014), 109.

${ }^{10}$ Charles Owen, “Structured Planning in Design: Information-Age Tools for Product Development”, Design Issues, Vol. I7, n. I (200I): 27-43.
} 
that it simply becomes 'what to make?', becomes a one-step process is where 'an already determined concept is turned into a specification' thereby already limiting the possibilities of the designing process.

This is very pertinent to landscape architecture, where a tradition of dealing with 'the site' can result in looking only towards site solutions in the exploration of a question. However, it may not be the site that holds the innovative potential for exploring the question - there may be more imaginative scope in an expansive framing, investigating for example the prospect of a hand-held device as much as a designed place, or an item of footwear as much as a boardwalk.

Projects are most powerfully framed around research questions that are honed through a multidisciplinary literature review. Selecting research questions of active interest to other academic fields allows comparison of design-based findings with results from other disciplinary fields and methods". For example design-directed research within the lab uses work by tourism geographers working in the field of protected areas and wilderness values to provide a platform of peer-reviewed research from which to generate questions. Tourism geography has identified a generally agreed position where wilderness is something that can only be diminished and lost. Multiple studies over the last twenty years continue this positioning with the following emblematic: "further work will also demonstrate the rate at which wilderness is declining, through changing perceptions and development patterns, and it is hoped that this [research] will provide the basis for the preservation of wilderness on one hand and the opportunity to maximise wilderness experiences for as many as possible on the other" 12 .

Within the lab this underlying premise of a reducing wilderness is critiqued, with the challenge and interrogation becoming generative in design terms, with questions like: can wilderness be created; can the mechanisms by which it is created be designed; and what forms could such mechanisms take? These investigations have drawn on phenomenological framings of landscape that can stimulate and strengthen 'practices of the wild' and with it increase wilderness's perceptual, conceptual and physical realm ${ }^{13}$. Design interventions have taken the forms of wayfinding systems, apps and volunteering projects ${ }^{14}$.

Questioning as a core strategy in working with the design laboratory emphasises research as active, rather than the passivity which can result from selecting a topic. A focus on a defined topic tends to lead to closing down rather than opening out. One of the useful tactics in opening-out is a form of questioning known as the Five Whys (championed by design consultancy IDEO), an approach which peels layers off assumed understandings of a situation, and like Owen's graph can cast a problem into a very different context. Industrial engineer Gary jing offers an example of how the Five Whys can derail path dependency in the exploration of a design problem, noting how at the Jefferson Memorial

\footnotetext{
" See John Law, After method: Mess in social science research, (London: Routledge, 2004).

${ }^{12}$ Geoff Kearsley, Andy Kliskey, James E. S. Higham, Perception of wilderness in the South Island of New Zealand: a multiple images approach (Dunedin, N.Z.: Centre for Tourism, University of Otago, 1999): 20.

13 Mick Abbott, "From Preserve to Incubator: Giving a New Meaning to Wilderness", in M. Abbott and R. Reeve (eds.). Wild Heart: the Possibility of Wilderness in Aotearoa New Zealand (Otago University Press, Dunedin, 1999).

${ }^{14}$ Mick Abbott, "Practices of the wild: a rewilding of landscape architecture". LA Plus (University of Pennsylvania, 20I5), I: 34-39.
} 
in Washington DC, an issue with crumbling stone had arisen ${ }^{15}$. Rather than simply treating the stone itself in the rush to find an answer, unpacking the problem repositioned the challenge:

- Why does the memorial deteriorate faster? Because it gets washed more frequently.

- Why is it washed more frequently? Because it receives more bird droppings.

- Why are there more bird droppings? Because more birds are attracted to the monument.

- Why are more birds attracted to the monument? Because there are more fat spiders in and around the monument.

- Why are there more spiders in and around the monument? Because there are more tiny insects flying in and around the monument during evening hours.

- Why are there more insects? Because the monument's illumination attracts more insects.

Through researching the problem the imaginative scope for this landscape-based problem was revealed not to simply fix the stone, but to turn the lights on an hour later each night, thus avoiding the infestation of tiny insects.

\section{Collaborating}

Design as laboratory invokes a sciences model, emphasising collective research, where different research teams work on key aspects of shared questions. As a physical, shared space the DesignLab establishes a collaborative research setting which fosters ongoing discussion and exploration, where intensive moments of ideation can be at the same time tested and critiqued. This is in distinction to the 'study alone' office settings that are the norm for most humanities-based researchers. The concept of the lab draws on science as a model, particularly in recognising the potency of co-operative and collective research activity.

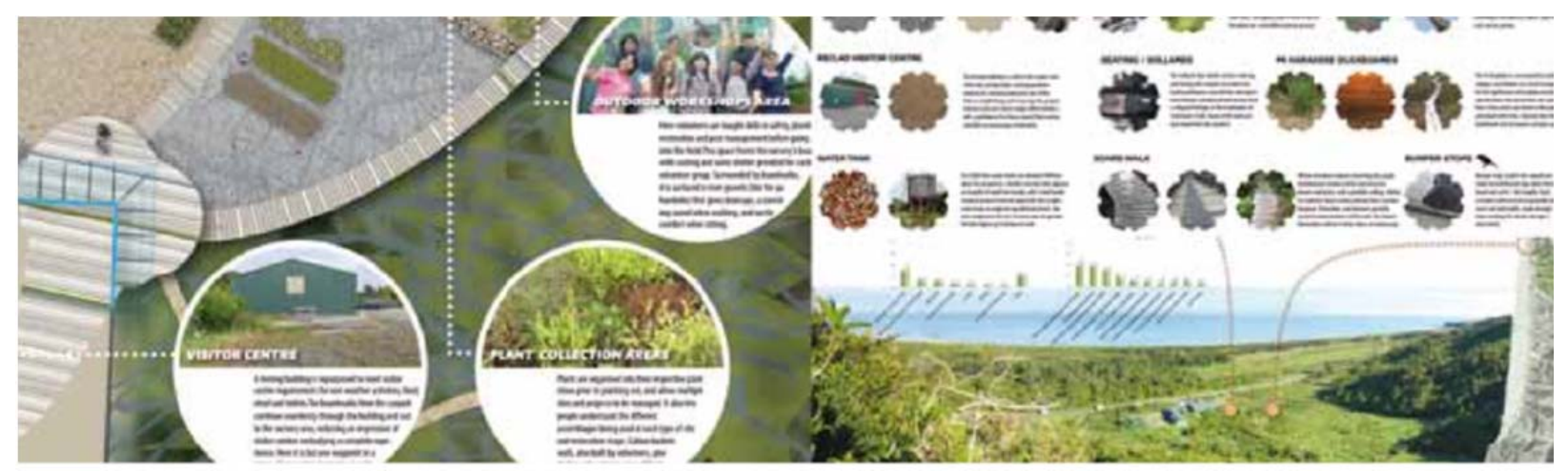

Figure I. Punakaiki Project, $\underline{w w w . d e s i g n l a b . a c . n z}$

Central to a strategy of collaboration is the fact that not-collaborating is a risky business. Adopting an autonomous and non-collaborative stance when involved in problems in a landscape setting would profoundly limit the prospects for innovation. No one, and no

${ }^{15}$ Gary G. Jing, "Flip the Switch,” Quality Progress, October (2008): 50-55. 
discipline, alone holds the breadth of knowledge needed to effectively explore problems. Landscope DesignLab projects actively engage with other disciplines within the university, as well as wider stakeholders. The Punakaiki project, working with Rio Tinto, Conservation Volunteers NZ, Department of Conservation and ecologists from Lincoln University, seeks to increase the ecological potency of a retired mining site. Landscape architecture sought to express a desire for citizen science into an integrated, site-based expression of 'voluntourism', and collective restoration as a vehicle for transferring the land into neighbouring National Park through the very actions of people. In this research it was identified that National Parks have the capacity to afford experience that support widely held values of conservation, including protecting the environment, native species, and the country's green image, and beyond default activities of walking and camping ${ }^{16}$ (Figure 2).

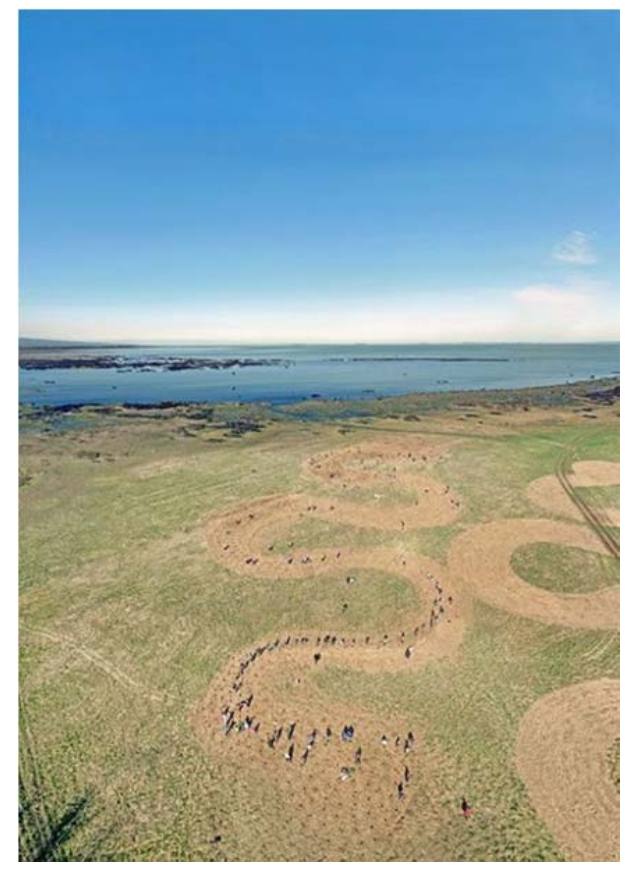

Figure 2. Ararira Wetland Project, Te Waihora, www.designlab.ac.nz

In another design-directed research project collaboration with dairy companies, conservation managers, community trusts and interaction designers led to a crowdsourced planting practice and resulting form that explicitly expressed through the actions of people forms of eel, inaka and/or river forms to build place attachment within public conservation lands (Figure 3).

\section{Designing}

The focus for DesignLab is working within research questions that are engaging a number of disciplines such that design's role is focused on increasing the imaginative scope and innovation potential, supporting methodological strengths in design including scenarios,

\footnotetext{
${ }^{16}$ Department of Conservation, Department of Conservation National Survey Report 4: Attitudes to Conservation, Wellington, 20II, 7. http://www.doc.govt.nz/Documents/about-doc/role/visitorresearch/attitudes-to-conservation.pdf.
} 
design, synthesis and diagramming. ${ }^{17}$ Design-directed research enlists both generative processes such as ideation, as well as analytical techniques like critique.

Designing is not undertaken with the intent of producing abstract exemplars. Rather the process is more restless: an opening out of terrain rather than placing a declaratory stake in the ground. In drawn form it concurs with architect Frank Gehry's statement: "If you watch me draw-actually draw-you'll see it's a frantic kind of searching". ${ }^{8}$ Strategically this process takes on multivalent characteristics including applying multiple programmatic drivers with which to build possibility. In work undertaken to imagine a 'Drylands Park' in New Zealand's Mackenzie Basin, a distributed form evolved that at times accommodated multiple forms of protection, elsewhere pan-region trails, pastoral grazing, tourism ventures and farm-based experiences (Figure 4).
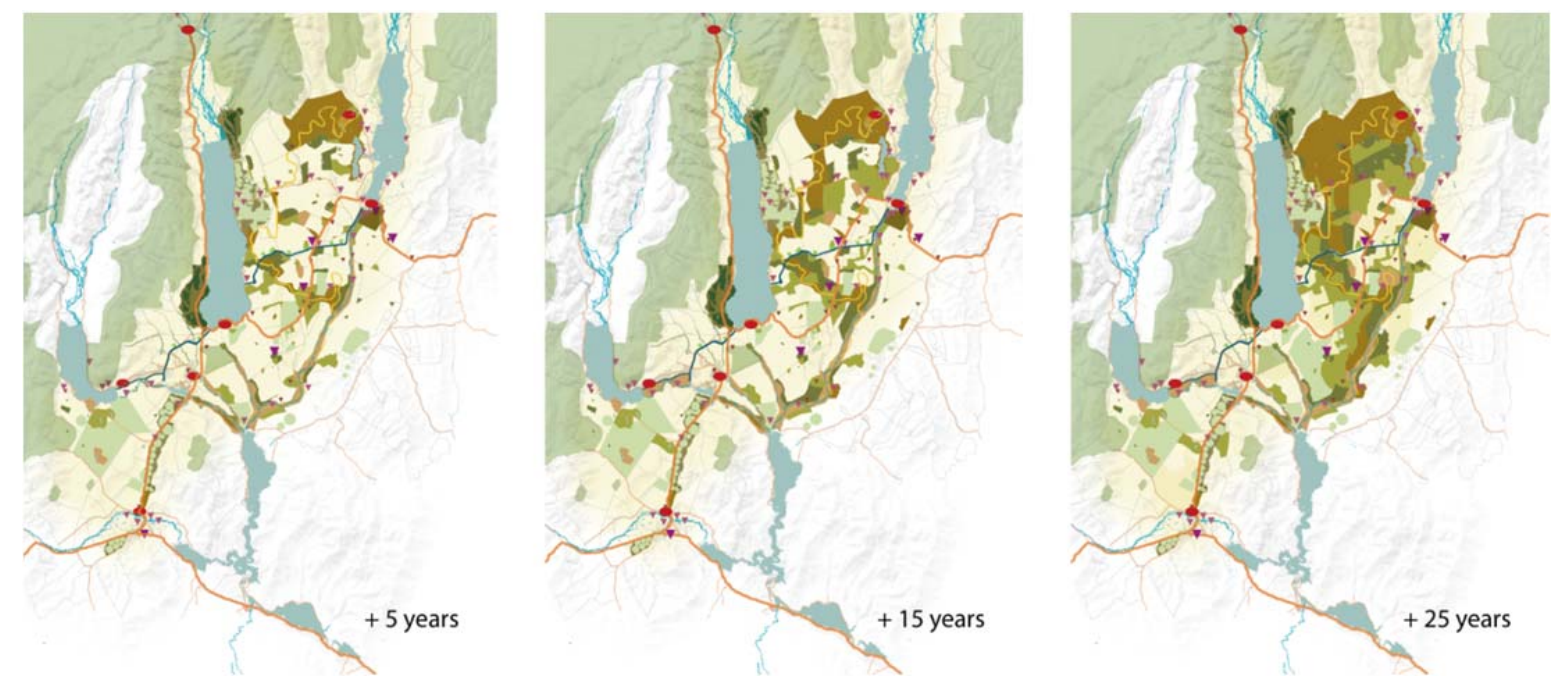

Figure 3. Mackenzie Basin Distributed Park, www.designlab.ac.nz

Such methods apply the use of matrices to facilitate cross-pollination, bringing together elements which may not have been used in an interrelated way before, like the 'knight's move' - the oblique operation where things not linearly connected are combined in unexpected ways. ${ }^{19}$ In Figure 5 students at Lincoln University's School of Landscape Architecture are undertaking a concept generation activity to shift communication-centric design proposals focusing on individuals to those that emphasise interaction and the building of social value. In the exercise, concepts are located according to two axes: individual-collective and communication-interaction. Students then determine design strategies to 'shift' their concepts further along the collective and interaction continuum.

\footnotetext{
${ }^{17}$ See Carter, Material Thinking and James Corner, "Eidetic operations and new landscapes," in Recovering landscape: essays in contemporary landscape architecture, ed. James Corner (New York: Princeton Architectural Press, 1999), 153-169.

${ }^{18}$ Bickford Arnell, Frank Gehry: Buildings and Projects, (New York: Rizzoli, 1985).

${ }^{19}$ Viktor Shklovsky, Zoo, or Letters not about Love, (Emwood Park, IL, Dalkey Archive Press, 200I), 103.
} 


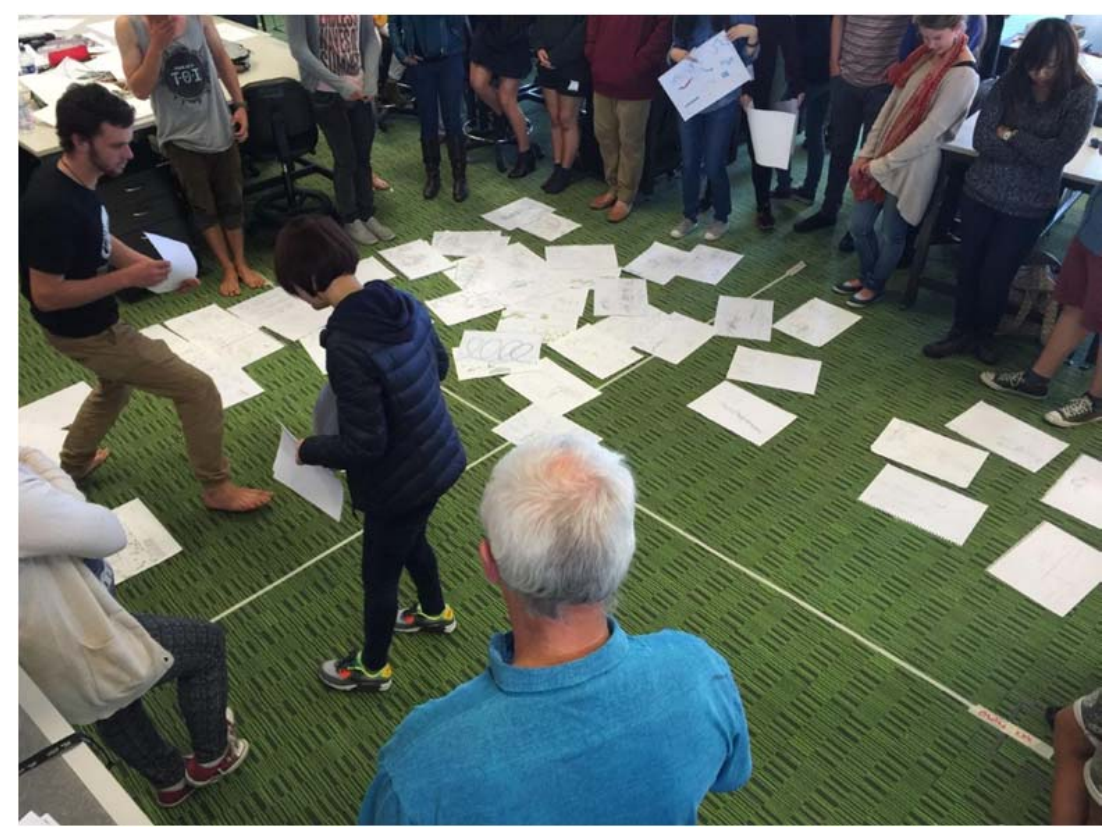

Figure 4. Students using a matrix to generate design responses, Charlotte Murphy

A quadrant approach based on intersecting axes, or "quattro stagioni, ${ }^{20}$ can similarly be both analytical and generational, where the two axes set out a field of possibility. In the context of memorial design, we used this approach to critique existing memorials in terms of their form and their temporal qualities. A formal continuum between object and place, and a temporal continuum between static and changing were set up to provide an armature for critique. Opposing these two axes creates the more powerful design-based device of the four quadrant array. Utilising the opportunity of a workshop with practitioners familiar with emotions and rituals, the quadrant tool was used as a kind of crowd-sourced design critique. The workshop sought to identify the ways in which memorials can operate, and the example here is based on an analysis of the Gibellina Earthquake Memorial in Sicily. Each practitioner recorded their responses on the axes, and these were subsequently overlaid to reveal areas of concentration, and areas of absence (Figure 6). The distribution of dots - each reflecting one person's critique reveals how the reading of one site can be nuanced across a range of interpretations. Design generation can subsequently be leveraged off an analysis process such as this, where the process of questioning can prompt exploration and create briefs. For example, what is a memorial which is a changing object, versus a memorial which is a changing place? How can a memorial be both static and changing? And perhaps both object and place?

20 'Quattro stagioni' is Four Seasons, with reference to the pizza topping that has four different flavours dividing the circular pizza into four quadrants. This term was first used in the context of design thinking by Wolfgang Jonas, drawing on the work of Peter Schwartz, The Long View (Doubleday). 


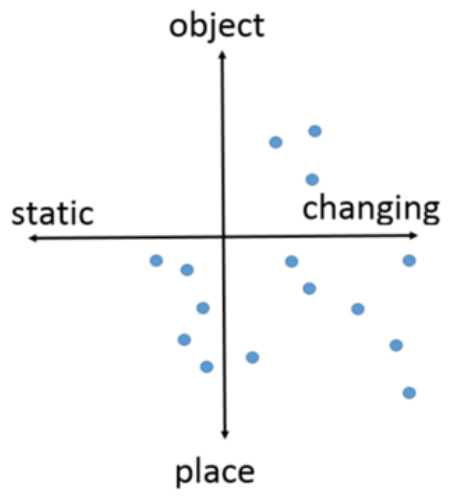

Figure 5. Mapping to identify spread of design critique positions across a range of practitioners for a specific memorial design. Values of place takes priority over object, while perceptions of the memorial according to static and changing dimensions are evenly split. Jacky Bowring

\section{Grounding}

Context, environment and project are never generic. Design-as-laboratory seeks out in the tangible a test bed for the value and validity of theoretical frameworks. ${ }^{21}$ Landscope DesignLab grounds research in place, recognising how creative research must be simultaneously within the universal and the local. Paul Carter expresses this eloquently with an analogy to weaving:

The warp is composed of the threads extended lengthwise in the loom. These can be thought of as the culture's myth lines, the grand narratives in terms of which it defines its sense of place and identity. But these linear narratives can neither cohere to form a pattern nor be subverted and overturned, unless the shuttle of local invention is at work, casting its woof-thread back and forth, over and under the warp-threads. Only in this way can cultures collectively gain agency over their story lines, learning to become themselves at this place. But to take control in this way, to represent a society locally reinventing itself, the shuttle has to advance, creeping progressively crosswise along the warp. ${ }^{22}$

Landscope's Eden NZ project is borne on the strategy of grounding. While the originating concept of an immersive environment with exhibition and education dimensions stems from Cornwall in the U.K., the New Zealand iteration is emphatically of this place. The location, form and focus of Eden NZ are about here, and they explore the question at the core of the project: how might a significantly degraded environment be used as an opportunity for re-focusing Christchurch's relationship with its waters and lands, and values of Mahinga Kai, in the twenty-first century? The site of exploration is in Christchurch's residential red zone, an area necessarily abandoned following the earthquakes of 2010 and $201 \mathrm{l}$. One impact of the earthquakes was to lower the land level, which had the consequent effect of increases in flooding, raising questions over possible scenarios for cities faced by rising sea levels. ${ }^{23}$ With water, rather than Eden UK's plants, as a focus, this project is tuned into issues that are pressing at global, regional and local levels. It is not only inundation with water that is being explored, but Canterbury, the province in which Christchurch is located, has a relatively dry climate and irrigation is both a problem and an opportunity in the highly modified landscape. Sails

\footnotetext{
${ }^{21}$ See Law, After method.

${ }^{22}$ Carter, Material Thinking, II.

${ }^{23}$ Nicki Copley, Jacky Bowring and Mick Abbott, "Thinking ahead: design-directed research in a city which experienced fifty years of sea-level change overnight". JOLA: Journal of Landscape Architecture, (Taylor and Francis, 20I5), 2: 78-89.
} 
speak of ocean migrations, plantings of ecological restoration and rivers of revitalised aquatic ecology. Here design is negotiating Christchurch's transition - both materially and perceptually - from its location on the plains - a landscape - to its place within rising seas and aquifers - a waterscape as well. The woof-thread carries these water stories through the overarching warp threads of wider narratives, with Eden NZ becoming the place of grounding that is derived from its environment rather than brand (Figure 7).
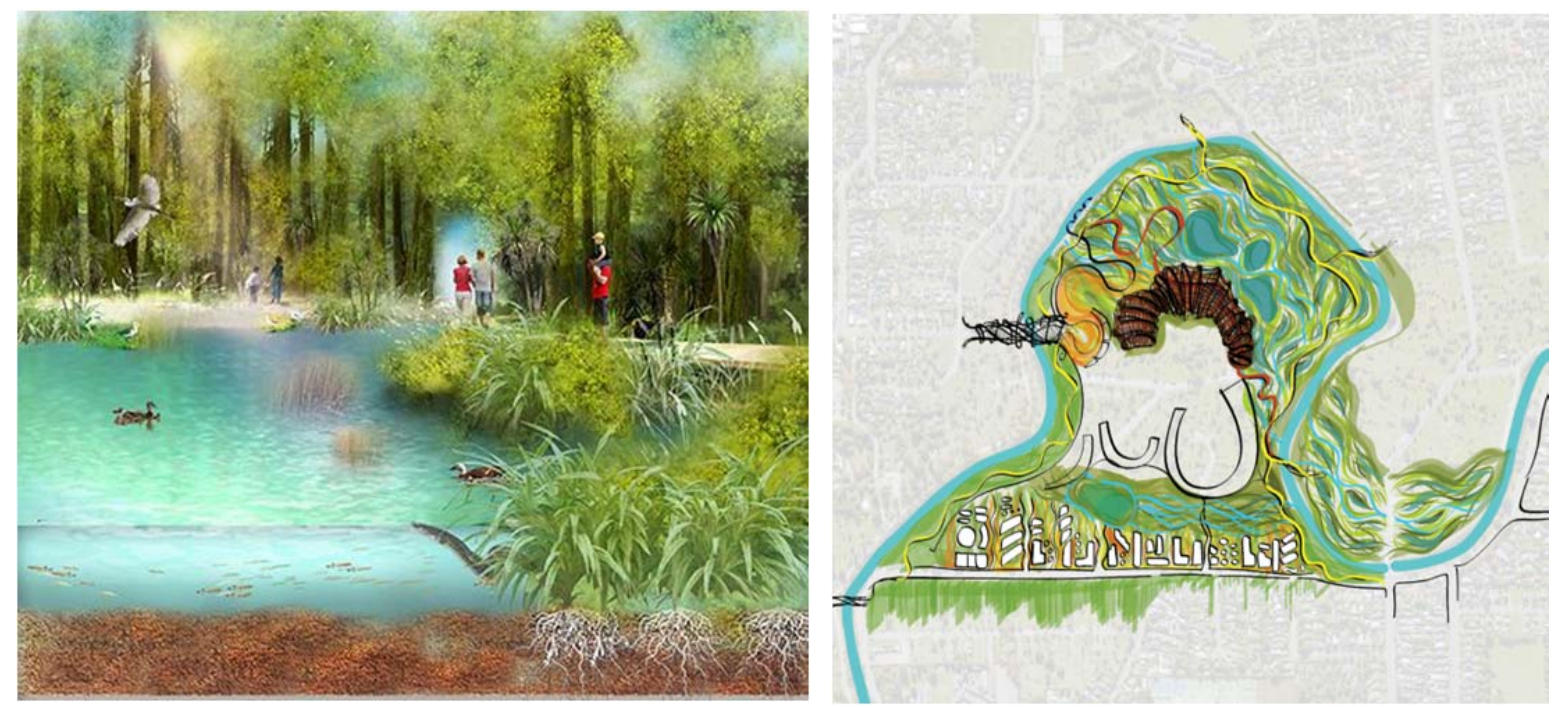

Figure 6. Ki Uta Ki Tai / Mountains to Sea Eden Project, Christchurch Red Zone, www.designlab.ac.nz

\section{Communicating}

Perhaps the most powerful added value in creative research comes with its communication. Landscope DesignLab, committed to presenting findings so researchers in other disciplines, can incorporate findings into future research projects and/or wider stakeholder applications. Design has particular strengths in generating compelling visual, time-based and three-dimensional form that make comparative differences, and analysis, readily discernible. As part of the wider collaborative process, the communication of findings is a value that design brings to the table.

Images do not only represent, they enable. Elsewhere we have considered Moir's 1925 map of Fiordland and statements of 'unexplored at present' that is written across blank areas. ${ }^{24}$ Not only does this describe the current condition but also it instrumentally shapes a changed future condition. It was this map that prompted people to travel to these areas to explore and change its existing status. Imagery developed by the lab for $\mathrm{Te}$ Whenua Hou (Figure 8) provided the impetus for the subsequent planting regime which has led to a further 750,000 native species to be planted that forms a bridge for birds (mimicking the form of a braided river) that connects the Southern Alps to Banks Peninsula.

\footnotetext{
${ }^{24}$ Mick Abbott, "Visualising a Temporal Cartography of Wilderness Travel”, in Antoni Moore and Igor Drecki (eds.) Cartographies for Tomorrow: Mapping in a Mashed-Up World (Springer, Heidelberg, 20I3).
} 


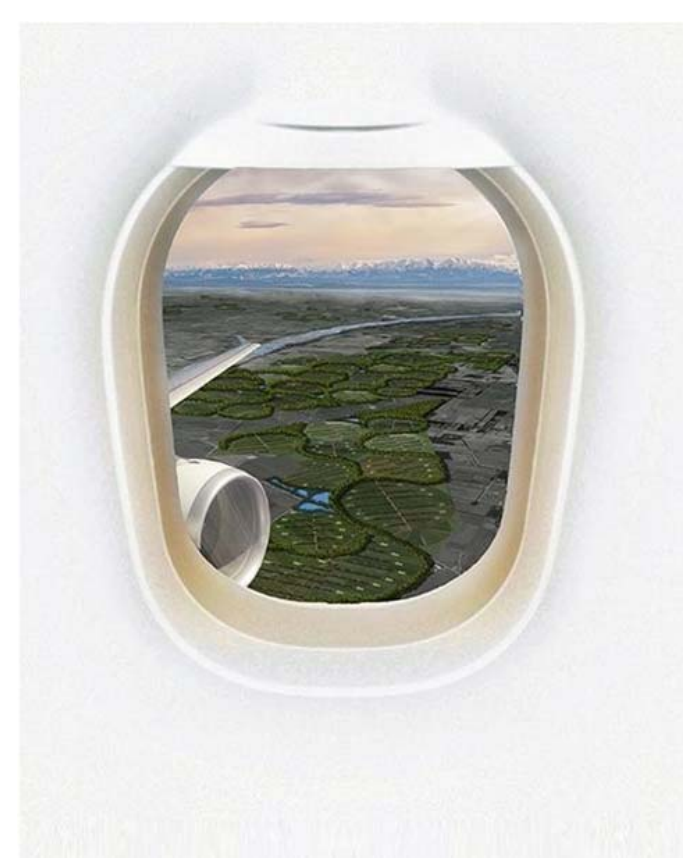

Figure 7. Whenua Hou Distributed Forest, Canterbury Plains, www.designlab.ac.nz

Communication of design-directed research must often connect with lay audiences which range from scientists unfamiliar with the language of design, to stakeholders unfamiliar with both science and design.

\section{Conclusions}

While much energy can be used in defending design as a research method, as Cross advises, design researchers "must concentrate on the 'designerly' ways of knowing, thinking and acting. ... Design practice does indeed have its own strong and appropriate intellectual culture, and ... we must avoid swamping our own design research with different cultures imported either from the sciences or the arts"25. The specific designdirected research projects incorporated in this paper demonstrate the possibility and efficacy of design- directed research, and an expanded scope for both landscape architecture research, and also its value for themes of inquiry in the wider academic world.

Here design research is content in that more formless realm of the nearly coming into being - a site that fosters imaginative scope rather than a capacity to render a solution in a manifest of schedules and sub-contracts.

Within research cultures design's new knowledge is not only identified from within its own body of work, but in reference to wider research endeavours drawn from across universities, other research institutions, and research partners. Peer review of the Punakaiki Volunteering Project comes also from the fields of Ecology and Mining

${ }^{25}$ Nigel Cross, “Designerly Ways of Knowing: Design Discipline Versus Design Science,” Design Issues, Vol. I7, n. 3 (200I): 49-55. 
reclamation ${ }^{26}$, work with Te Whenua Hou from ecology, and international farm and landscape practice. ${ }^{27}$

Design-as-Laboratory firmly locates design into the world of research questions and with it charts a course for a strengthening and more strategic role for design that is located at the core of inquiry and scholarly research. As such the Design-as-Laboratory is in itself positioned as form of methodological question, which seeks out experimentation and heterogeneity in approaches that orientates research through designing outward: to proactively introduce itself into wider research sites where values of multidisciplinarity, collaboration and multiple modes of inquiry are fostered.

${ }^{26}$ CMS Smith, M.H. Bowie, J.L. Hahner, S. Boyer, Y.-N. Kim, H.-T. Zhong, M. Abbott, S. Rhodes, D. Sharp, N. Dickinson, "Punakaiki Coastal Restoration Project: a case study for a consultative and multidisciplinary approach in selecting indicators of restoration success for a sand mining closure site, West Coast, New Zealand2, Catena, Vol. I36 (2015): 91-103.

${ }_{27}$ Mick Abbott, Kate Blackburne, Jacky Bowring and Charlotte Murphy, "Fraktales Pflanzen in Aotearoa Neuseeland", Anthos. The Swiss Journal of Landscape Architecture, Vol. 3, n. 16 (2016): 42-44.

52 | The Journal of Public Space, 2(3), 2017 | Special Issue | ISSN 2206-9658

(C) Queensland University of Technology 